\title{
SCALP HIGH FREQUENCY OSCILLATION RATE DEPENDS ON SLEEP STAGE AND DECREASES WITH TIME SPENT IN SLEEP
}

Running title: Impact of sleep on scalp HFO rate

Dorottya Cserpan ${ }^{1,2}$, Richard Rosch ${ }^{1}$, Santo Pietro Lo Biundo ${ }^{1}$, Johannes Sarnthein ${ }^{2,3,4}$, Georgia Ramantani $i^{1,3,5}$

${ }^{1}$ Department of Neuropediatrics, University Children's Hospital Zurich, Switzerland

${ }^{2}$ Department of Neurosurgery, University Hospital Zurich, Switzerland

${ }^{3}$ University of Zurich, Switzerland

${ }^{4}$ Klinisches Neurozentrum Zürich, University Hospital Zurich, Switzerland

${ }^{5}$ Children's Research Centre, University Children's Hospital Zurich, Switzerland

Correspondence to: Georgia Ramantani, MD, PhD; Neuropediatrics, University Children's Hospital Zurich, Steinwiesstrasse 75, 8032 Zurich, Switzerland; phone: +41 4426675 92; email: georgia.ramantani@kispi.uzh.ch 
medRxiv preprint doi: https://doi.org/10.1101/2021.04.19.21255728; this version posted April 22, 2021. The copyright holder for this preprint

(which was not certified by peer review) is the author/funder, who has granted medRxiv a license to display the preprint in perpetuity.

It is made available under a CC-BY 4.0 International license.

\begin{abstract}
High frequency oscillations (HFO) in scalp EEG are a new and promising epilepsy biomarker. HFO analysis is typically restricted to random and relatively brief sleep segments. However, considerable fluctuations of HFO rates have been observed over the recording nights, particularly in relation to sleep stages and cycles. Here, we identify the timing within the sleep period and the minimal data interval length that allow for sensitive and reproducible detection of scalp HFO. We selected 16 seizure-free whole-night scalp EEG recordings of children and adolescents with focal lesional epilepsy (median age $7.6 \mathrm{y}$, range 2.2-17.4 y). We used an automated and clinically validated HFO detector to determine HFO rates $(80-250 \mathrm{~Hz})$ in bipolar channels. To identify significant variability over different NREM sleep stages and over time spent in sleep, we modelled HFO rate as a Poisson process. We analysed the test-retest reliability to evaluate the reproducibility of HFO detection across recording intervals. Scalp HFO rates were higher in N3 than in N2 sleep and highest in the first sleep cycle, decreasing with time spent in sleep. In N3 sleep, the median reliability of HFO detection increased from $67 \%$ to $79 \%$ to $100 \%$ for 5-, 10-, and 15-min data intervals, improving significantly ( $p=0.004)$ from 5 to $10 \mathrm{~min}$ but not from 10 to $15 \mathrm{~min}$. In this analysis of whole-night scalp EEG, we identified the first N3 sleep stage as the most sensitive time window for HFO rate detection. N3 data intervals of 10 min duration are required and sufficient for reliable measurements of HFO rates. Our study provides a robust and reliable framework for implementing scalp HFO as an EEG biomarker in pediatric epilepsy.
\end{abstract}

Keywords: pediatric focal epilepsy, scalp EEG, high frequency oscillations, HFO, sleep

Abbreviation list:

AASM: American Academy of Sleep Medicine

AIC: Akaike Information Criterion

DBA: Delta Band Activity

Eol: Events of Interest

FCD: Focal Cortical Dysplasia

HFO: High Frequency Oscillations

NREM: Non-Rapid Eye Movement sleep

SBA: Sigma Band Activity 
medRxiv preprint doi: https://doi.org/10.1101/2021.04.19.21255728; this version posted April 22, 2021. The copyright holder for this preprint (which was not certified by peer review) is the author/funder, who has granted medRxiv a license to display the preprint in perpetuity. It is made available under a CC-BY 4.0 International license .

\section{INTRODUCTION}

High frequency oscillations (HFO) in scalp EEG are a new and promising non-invasive epilepsy biomarker providing added prognostic value, particularly in the pediatric population (Boran et al., 2019; Ohuchi et al., 2019; Nariai et al., 2020; Tsuchiya et al., 2020; Cserpan et al., 2021). Beyond the initial use of HFO to delineate the epileptogenic zone in epilepsy surgery, HFO are currently investigated as potential biomarkers of epileptogenesis, seizure propensity, disease severity, and treatment response (Jacobs and Zijlmans, 2020; Gotman, 2021). The utility of scalp HFO as EEG-biomarker in pediatric epilepsy has been substantiated by recent studies corroborating the correlation of scalp HFO rates with (1) epileptogenesis after a first epileptic seizure, regardless of aetiology (Klotz et al., 2021), (2) seizure propensity in the presence of a predisposing condition such as centrotemporal spikes (Kramer et al., 2019) or tuberous sclerosis (Bernardo et al., 2018), (3) disease severity in focal lesional epilepsy (Boran et al., 2019) as well as in a wide range of pediatric epilepsy syndromes (Toda et al., 2015; van Klink et al., 2016; Ikemoto et al., 2018; Nariai et al., 2020); (4) treatment response following the administration of drugs or epilepsy surgery (Kobayashi et al., 2015; Boran et al., 2019). HFO analysis in patients with epilepsy is typically restricted to random and relatively brief time periods of mostly 5-30 min, even in those undergoing long-term EEG recordings (Zelmann et al., 2014). However, the question remains whether all available data, over several nights, should be utilised for analysis or whether carefully selected segments suffice for clinically meaningful results (Fedele et al., 2019). Data selection will have to balance the need for stable estimates of, e.g., HFO localisation patterns and rates that accurately reflect network properties (Gliske et al., 2018; Fedele et al., 2019; Chen et al., 2021) against the benefits of shorter segments making this approach more widely applicable, even in short standard EEGs. This makes the appropriate choice of the most suitable time windows and sample size to ensure data quality and representativity essential.

HFO analysis is routinely performed in sleep to avoid contamination by muscle artefacts (Zijlmans et al., 2017). However, considerable fluctuations of HFO rates have been observed across sleep stages and cycles (Staba et al., 2004; Bagshaw et al., 2009; Dümpelmann et al., 2015; von Ellenrieder et al., 2017; Gliske et al., 2018), analogous to the significant modifications in the rates of spikes, the standard EEG-biomarker of epilepsy. For spikes, a meta-analysis based on both scalp and invasive EEG revealed higher occurrence rates in NREM (N3) sleep compared to other vigilance states (Ng and Pavlova, 2013). Similarly, pathological HFO rates were shown to be highest during NREM sleep in invasive EEG studies in drug-resistant focal epilepsy (Staba et al., 2004; Bagshaw et al., 2009; von Ellenrieder et al., 2017; Al-Bakri et al., 2018) and, most importantly, pathological HFO during NREM sleep were shown to best localise the epileptogenic zone (Klimes et al., 2019). Furthermore, pathological HFO rates have recently been shown to decrease with accumulated time in sleep in invasive recordings (von Ellenrieder et al., 2017), pointing to data from the first sleep cycle as being most best suitable for analysis, allowing the most sensitive detection of HFO. However, it is unclear if findings from invasive EEG in mainly adult cohorts with drug-resistant focal epilepsy undergoing presurgical evaluation apply to scalp EEG recordings across childhood and adolescence and in a broader range of epilepsy syndromes. Despite being crucial for implementing HFO as a clinical tool, the 
medRxiv preprint doi: https://doi.org/10.1101/2021.04.19.21255728; this version posted April 22, 2021. The copyright holder for this preprint (which was not certified by peer review) is the author/funder, who has granted medRxiv a license to display the preprint in perpetuity.

It is made available under a CC-BY 4.0 International license.

relationship between sleep and scalp HFO characteristics in pediatric epilepsy remains insufficiently explored.

To address the hypotheses that scalp HFO rate is highest in the N3 sleep stage and decrease with accumulated time in sleep, we retrospectively analysed whole-night scalp EEG recordings of children and adolescents with focal lesional epilepsy, implementing a previously validated automated HFO detector (Fedele et al., 2016, 2017; Boran et al., 2019; Cserpan et al., 2021). While our previous study addressed the impact of patient age on scalp HFO (Cserpan et al., 2021), here we investigated changes in scalp HFO rate across different sleep stages and cycles to verify whether sleep-related factors explain the variability in HFO rate during sleep and determine optimal data selection strategies to identify HFO rate distributions across the scalp reliably.

\section{METHODS}

\section{Patient recruitment}

We recorded whole-night video-EEGs from 72 children and adolescents (< 18 y) with epilepsy at the University Children's Hospital Zurich between January 2020 and January 2021. For the current study focusing on the effect of sleep homeostasis on scalp HFO rates, we included 16 patients that 1) were diagnosed with focal lesional epilepsy based on electroclinical correlations and imaging findings, 2) had a whole-night scalp EEG recording obtained at a high sampling frequency (>1000 Hz), and 3) had no seizures during the recording night. The clinical purpose of whole-night EEG included presurgical evaluation and treatment monitoring.

\section{Scalp EEG recording \& data selection}

Patients underwent whole-night video-EEG with 21 electrodes placed according to the international 10-20 system at a $1024 \mathrm{~Hz}$ sampling rate using the Micromed $\AA$ EEG recording system (Mogliano Veneto, Treviso, Italy). Impedances were typically $\leq 1 \mathrm{k} \Omega$. Sleep stages were marked by experienced neurophysiologists according to the American Academy of Sleep Medicine (AASM) (Berry et al., 2017). We selected only N2, and N3 sleep stages for further analysis since muscle activity and movement artefacts in wakefulness and REM sleep interfere with HFO detection, leading to increased false positives (Zelmann et al., 2014). We divided the selected data into 5-min intervals for further processing. Scalp EEG intervals with visible artefacts and channels with continuous interference based on visual inspection were excluded from further analysis.

HFO detection and analysis were performed blinded to clinical characteristics of the patients, and the results from HFO analysis were not considered for clinical decision making.

\section{Automated HFO detection}

To capture the HFO activity with the highest possible spatial resolution given the data, we rereferenced to a bipolar montage using all combinations of neighbouring electrodes and thus obtained 52 bipolar channels. 
medRxiv preprint doi: https://doi.org/10.1101/2021.04.19.21255728; this version posted April 22, 2021. The copyright holder for this preprint (which was not certified by peer review) is the author/funder, who has granted medRxiv a license to display the preprint in perpetuity. It is made available under a CC-BY 4.0 International license .

Scalp HFO detection was conducted with a clinically validated, automated HFO detector (Fedele et al., 2016, 2017; Boran et al., 2019; Cserpan et al., 2021) that operates in three stages. Stage I determines a baseline amplitude threshold in time intervals based on the Stockwell entropy value in the ripple band (80-250 Hz). Events exceeding the threshold are marked as events of interest (Eol). In Stage II, the detector selects all Eol that exhibit a highfrequency peak isolated from low-frequency activity in the time-frequency space. In Stage III, the detector rejects all Eol with amplitude $\geq 40 \mu \mathrm{V}$ or signal-to-noise ratio $<4$ or co-occurring in channels of the two hemispheres. There was no further visual validation of the events, rendering the algorithm fully automated.

We calculated the channel-wise HFO rate for each patient by dividing the number of detected HFO on each channel by the duration of the analysed EEG recording. For modelling purposes, we used the HFO count, i.e., the number of HFO events detected in each 5-min data interval, on the channel with the highest HFO rate during the recording night.

We controlled for the clinical plausibility of scalp HFO rate distributions by comparing the localisation of the channel with the highest HFO rate with the localisation of spikes in scalp EEG and focal lesions in MRI.

\section{Modelling approach}

We hypothesized that scalp HFO rates were modulated by sleep homeostasis. To identify significant effects of NREM sleep stage (N2, N3), and time spent in sleep on scalp HFO rates, we modelled the HFO rate as a Poisson process based on the methodology previously applied for HFO analysis in invasive EEG (von Ellenrieder et al., 2017). We assumed that HFO events are not overlapping and that time intervals between consecutive events are statistically independent (Nagasawa et al., 2012; Nonoda et al., 2016; von Ellenrieder et al., 2017). Primary variables of interest affecting HFO rates were the NREM sleep stage (N2, N3) and the time spent in sleep, determined as the elapsed time expressed in hours from the first sleep stage until waking up in the morning. We further included the delta band and the sigma band activity, estimated as the root-mean-square value of the bandpass filtered signal in the $0.5-4 \mathrm{~Hz}$ and the 10-16 Hz band during each 5-min data interval. The delta band and sigma band activity were calculated for the scalp channels F3-C4, F4-C4 and averaged, then normalised to have zero mean and unit variance for each analysed sleep stage and patient.

We used different combinations of the explanatory variables to create Poisson process models $(\mathrm{N}=15)$ to estimate the mean HFO rate for every 5-min data interval as a function of these variables and thus to provide statistical evidence for their contribution to the fluctuation of HFO rates during whole-night sleep. We considered the mean HFO rate calculated over the total analysed period and relative variations of the mean HFO rate as determined by the variables in the model. We used the Akaike Information Criterion (AIC) for model comparison (Burnham and Anderson, 2002) since its value indicates both the goodness-of-fit and the complexity of the model. The respective coefficients and the AIC values for all 15 models are given in Suppl.

Table 1. Two models can be considered significantly different with $95 \%$ probability when the difference in the respective AIC values exceeds 6 (Burnham and Anderson, 2002). To evaluate the performance of the Poisson process model, we used leave-one-out cross-validation using all but one patient from our cohort to estimate the model coefficients and testing the result on one 
medRxiv preprint doi: https://doi.org/10.1101/2021.04.19.21255728; this version posted April 22, 2021. The copyright holder for this preprint (which was not certified by peer review) is the author/funder, who has granted medRxiv a license to display the preprint in perpetuity. It is made available under a CC-BY 4.0 International license.

patient, then repeating this procedure for all patients. To further validate our modelling of dynamic changes in HFO, we compared the predicted HFO counts in the 5-min data intervals, 1) as given by the Poisson process model when including all patient data while training (Poisson process - train), 2) when cross-validating the model on the left-out patient (Poisson process test) model, with 3) the constant mean HFO rate model, according to the mean absolute error for each patient (Suppl. Table 2, Suppl. Figure 1).

\section{Test-retest reliability}

To evaluate the reproducibility of scalp HFO detection, i.e. to investigate whether channel-wise HFO rates are consistent among different data intervals for each patient, we applied the testretest reliability methodology as described in our previous work (Fedele et al., 2017). In short, we first calculated the normalised scalar products of HFO event vectors across different data intervals to depict the actual distribution and then created a null distribution from scalar products of HFO event vectors with permutated channel order. We report the mean number of scalar products with higher values than the 97.5 percentile of the null distribution, thus giving an estimation for the consistency of detected HFO rates in the analysed data intervals compared to randomised data. For this analysis step, we constructed 10-and 15-min data intervals for each patient by concatenating multiple 5-min data intervals.

\section{Statistics}

We calculate the mean HFO rate over all recording intervals of each patient. Across patients, we describe distributions by their median and their interquartile range (iqr). To compare these distributions, we used non-parametric statistics. We used the Wilcoxon signed-rank tests to compare the reliability values between sleep stages and data intervals of 5-, 10-, and 15-min duration. To quantify correlations, we used Spearman's rank correlation. Statistical significance was established at $p<0.05$.

\section{RESULTS}

\section{Patient characteristics, total length of sleep recordings, and HFO count}

We included 16 patients (4 female) with focal lesional epilepsy (Table 1). The median age at the time of the whole-night EEG recording was 7.6 y (range 2.2-17.4 y). Aetiology included focal cortical dysplasia in 8 cases, perinatal or childhood stroke in 3 cases, and single cases of diffuse glioma, hypothalamic hamartoma, Rasmussen's encephalitis, hippocampal sclerosis, and hemiconvulsion- hemiplegia-epilepsy syndrome. The localisation of the presumed epileptogenic zone was frontal in 4 cases, temporal in 3, frontocentral in 2, parietal and temporoparietooccipital in one case each, and hemispheric in the remaining 5 cases.

We analysed 3605 min of EEG data, including 2500 min of N2 and 1105 min of N3 sleep. In total, we detected 4621 HFO: 2636 in N2 and 1985 in N3 sleep. The median length of analysed data per patient was 210 min (iqr 67.5), with a median of 237.5 (iqr 323) detected HFO per patient. The median length of analysed data per patient was $132.5 \mathrm{~min}$ (iqr 87.5) for N2 and 67.5 min (iqr 42.5) for N3 sleep. 
medRxiv preprint doi: https://doi.org/10.1101/2021.04.19.21255728; this version posted April 22, 2021. The copyright holder for this preprint (which was not certified by peer review) is the author/funder, who has granted medRxiv a license to display the preprint in perpetuity.

It is made available under a CC-BY 4.0 International license .

\begin{tabular}{|c|c|c|c|c|c|c|c|}
\hline ID & Sex & Aetiology & $\begin{array}{l}\text { Localisation of the } \\
\text { epileptogenic zone }\end{array}$ & $\begin{array}{l}\text { Mean HFO } \\
\text { rate in total } \\
\text { (HFO/min) }\end{array}$ & $\begin{array}{l}\text { Mean HFO } \\
\text { rate in N2 } \\
\text { (HFO/min) }\end{array}$ & $\begin{array}{l}\text { Mean HFO } \\
\text { rate in N3 } \\
\text { (HFO/min) }\end{array}$ & $\begin{array}{c}\text { Channel } \\
\text { with the } \\
\text { highest } \\
\text { HFO rates }\end{array}$ \\
\hline 1 & $\mathrm{~m}$ & Postnatal stroke & L hemispheric & 3.8 & 3.2 & 4.6 & Fp1-Fz \\
\hline 2 & $\mathrm{~m}$ & FCD & $\mathrm{R}$ temporal & 3.1 & 2.1 & 5.0 & T6-P4 \\
\hline 3 & $f$ & FCD & $\mathrm{R}$ fronto-central & 2.4 & 2.6 & 2.1 & $\mathrm{~F} 4-\mathrm{Cz}$ \\
\hline 4 & $\mathrm{~m}$ & FCD & L parietal & 2.4 & 2.5 & 1.7 & F3-C3 \\
\hline 5 & $\mathrm{~m}$ & FCD & $L$ fronto-central & 1.8 & 1.6 & 2.3 & T5-C3 \\
\hline 6 & $\mathrm{~m}$ & $\begin{array}{c}\text { Hypothalamic } \\
\text { hamartoma }\end{array}$ & $L$ frontal & 1.6 & 1.6 & 1.7 & Pz-O1 \\
\hline 7 & $\mathrm{~m}$ & Perinatal stroke & $\mathrm{R}$ hemispheric & 1.4 & 1.3 & 1.4 & Fp2-F8 \\
\hline 8 & $f$ & FCD & $\mathrm{R}$ frontal & 1.3 & 0.3 & 2.6 & $\mathrm{P} 4-\mathrm{O} 2$ \\
\hline 9 & $f$ & $\begin{array}{l}\text { Rasmussen`s } \\
\text { encephalitis }\end{array}$ & L hemispheric & 0.6 & 0.3 & 0.9 & $\mathrm{C} 3-\mathrm{Fz}$ \\
\hline 10 & $\mathrm{~m}$ & FCD & $L$ frontal & 0.5 & 0.6 & 0.3 & Fp1-F3 \\
\hline 11 & $\mathrm{~m}$ & FCD & $\begin{array}{l}\text { L temporo-parieto- } \\
\text { occipital }\end{array}$ & 0.4 & 0.4 & 0.5 & Fp1-Fp2 \\
\hline 12 & $\mathrm{~m}$ & $\begin{array}{l}\text { Hippocampal } \\
\text { sclerosis }\end{array}$ & L temporal & 0.3 & 0.2 & 0.3 & F8-T4 \\
\hline 13 & $\mathrm{~m}$ & $\begin{array}{l}\text { Hemiconvulsion- } \\
\text { hemiplegia-epilepsy } \\
\text { syndrome }\end{array}$ & $\mathrm{R}$ hemispheric & 0.2 & 0.2 & 0.8 & Fp1-Fp2 \\
\hline 14 & $f$ & FCD & $L$ frontal & 0.2 & 0.2 & 0.3 & Fp1-F3 \\
\hline 15 & $\mathrm{~m}$ & Diffuse glioma & $\mathrm{R}$ temporal & 0.2 & 0.2 & 0.2 & Fp1-Fz \\
\hline 16 & $\mathrm{~m}$ & Perinatal stroke & $\mathrm{L}$ hemispheric & 0.1 & 0.1 & 0.2 & T3-P3 \\
\hline
\end{tabular}

Table 1: Patient characteristics and HFO properties.

Patient characteristics include the etiological substrate of their focal epilepsy and the lobar localisation of the presumed epileptogenic zone based on the electroclinical correlations and MRI findings. HFO properties include mean HFO rates in events/min in all analysed data intervals for the channel with the highest HFO rates in total and separately for N2 and N3 sleep.

y: years, f: female, m: male, nr: number, FCD: focal cortical dysplasia; nr: number; L: left; R: right

\section{The scalp HFO rate is higher in N3 than in N2 sleep}

The mean HFO rate over all data intervals $(\mathrm{N} 2+\mathrm{N} 3)$ varied widely between patients (median $0.9 \mathrm{HFO} / \mathrm{min}$, iqr 1.8), Table 1, Fig. 1A). The mean HFO rate was lower for N2 (median $0.5 \mathrm{HFO} / \mathrm{min}$, iqr 1.6) and higher for N3 (median 1.2 HFO/min, iqr 1.9) (Table 1). Across all patients, mean HFO rates in N3 were higher than in N2 (median 29\%, iqr 77; Wilcoxon signedrank test, $p=0.049, z=1.96)$ (Fig 1B). 
medRxiv preprint doi: https://doi.org/10.1101/2021.04.19.21255728; this version posted April 22, 2021. The copyright holder for this preprint (which was not certified by peer review) is the author/funder, who has granted medRxiv a license to display the preprint in perpetuity.

It is made available under a CC-BY 4.0 International license.

A

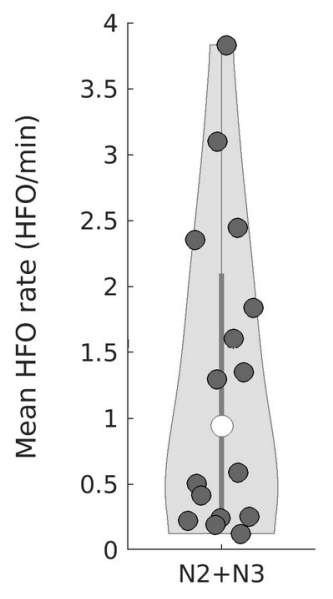

B

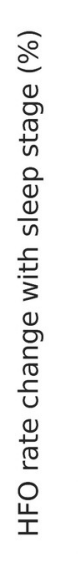

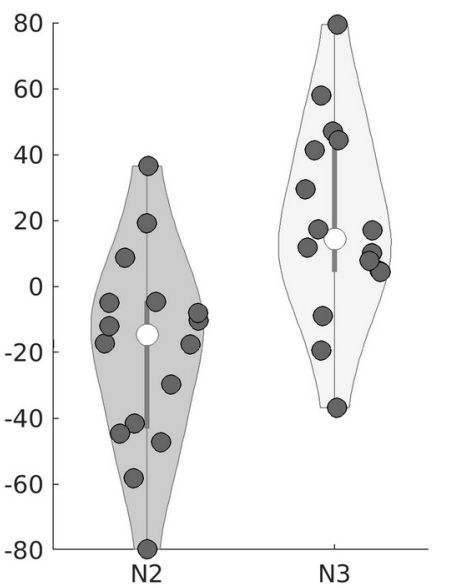

C

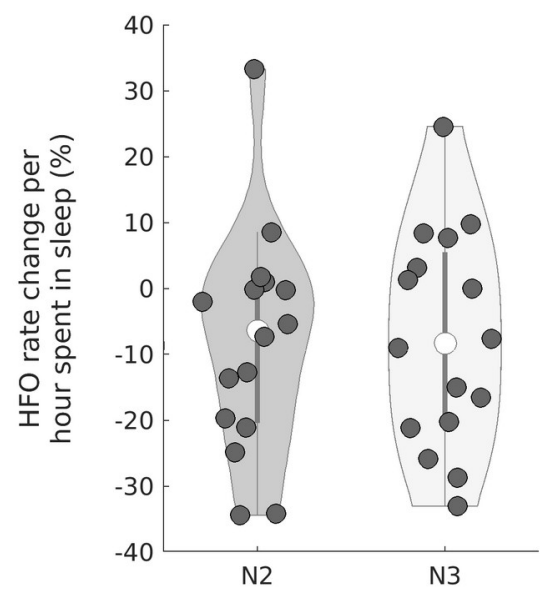

Figure 1. The mean HFO rate is higher in N3 and decreases with time spent in sleep.

The violin plot shows the median (white circle) and the interquartile range (grey perpendicular line) of each distribution. A) HFO rate averaged over all N2 and N3 intervals for each patient. B) Compared to the mean HFO rate shown in panel A, the mean HFO rate is lower for N2 intervals and higher for N3 intervals. C) The Poisson process model indicates that the HFO rate decreases per hour spent in sleep (N2 median -6.3\%, N3 median -8.3\%).

\section{The scalp HFO rate is higher in the first sleep cycle}

Figure 2 presents the hypnogram of Patient 2 with the respective delta- and sigma band activity and the HFO rate during $\mathrm{N} 2$ and $\mathrm{N} 3$, including both the measured rate and the rate estimated by the Poisson process model. The figure illustrates the decrease of the HFO rate with time spent in sleep for Patient 2.

To analyse the HFO rate across all patients, we used the Poisson process model. Based on the AIC values (Suppl. Table 1), the best model was the one including all four variables, i.e., sleep stage, time spent in sleep, delta and sigma band activity. The coefficients of the relative HFO rate variation for all four included variables, as estimated by the best model, are given in Table

2. The mean HFO rate decreased with time with a relative median rate change of $-6.3 \%$ (iqr 20.8) per hour in N2 and -8.3\% (iqr 26.1) per hour in N3 sleep (Figure 1C).

\begin{tabular}{|c|c|c|}
\hline & $\mathrm{N} 2$ & $\mathrm{~N} 3$ \\
\hline NREM sleep stage & $-16.4 \%$ & $30.6 \%$ \\
\hline Time spent in sleep & $-5.0 \%$ & $-2.1 \%$ \\
\hline Delta band activity & $9.8 \%$ & $23.2 \%$ \\
\hline Sigma band activity & $7.1 \%$ & $9.7 \%$ \\
\hline
\end{tabular}

Table 2. Estimated coefficients of relative HFO rate variation for the best model.

The relative HFO rate variation is defined as follows: a change of $X$ times in delta band activity is associated with a change in the HFO rate in N3 sleep of $0.232 X$ times. Both delta- and sigma band activity of the included N2 and N3 data intervals were normalised to zero mean and unit standard 
medRxiv preprint doi: https://doi.org/10.1101/2021.04.19.21255728; this version posted April 22, 2021. The copyright holder for this preprint (which was not certified by peer review) is the author/funder, who has granted medRxiv a license to display the preprint in perpetuity.

It is made available under a CC-BY 4.0 International license.

deviation. The mean HFO rate is higher in N3 than in N2 sleep and in the presence of delta- and sigma band activity, and it decreases with time spent in sleep by $5.0 \%$ and $2.1 \%$ per hour in N2 and N3 sleep.

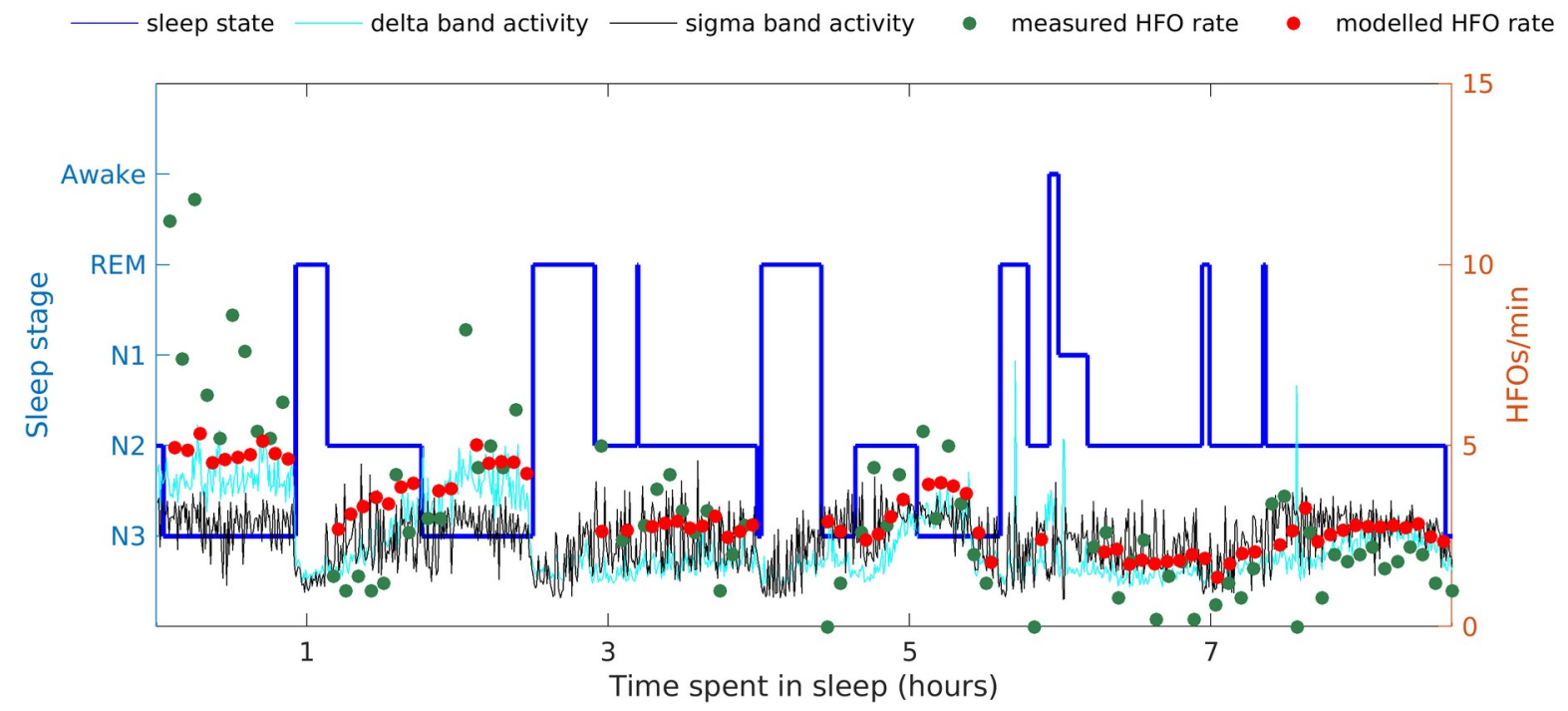

Figure 2. Hypnogram of a four-year-old patient with right temporal lobe epilepsy.

We present the hypnogram (dark blue line), the delta- and sigma band activity (light blue and black line), the measured HFO rate (green dots) and the modelled HFO rate (red dots) in N2 and N3 sleep as a function of time spent in sleep. The measured HFO rate is highest in N3 sleep and decreases with time spent in sleep.

\section{Higher scalp HFO rates correlate with higher delta- and sigma band activity.}

Delta- and sigma band activity positively correlate with HFO rates during both N2 and N3 sleep stages, while this correlation is considerably stronger for delta- than for sigma band activity (Table 2). On a group level, an increase of one standard deviation in the delta band activity is associated with 23.2\% higher mean HFO rates for N3 and 9.8\% higher mean HFO rates for N2 sleep, whereas an increase of one standard deviation in the sigma band activity correlates with $9.7 \%$ higher mean $\mathrm{HFO}$ rates for $\mathrm{N} 3$ and $7.1 \%$ higher mean HFO rates for $\mathrm{N} 2$ sleep compared to the mean HFO rates.

\section{N3 data intervals of 10 min are required for HFO analysis}

We calculated the test-retest reliability of HFO detection in 5-, 10-, and 15-min data intervals (Fig. 3). For 5-, 10-, and 15-min data intervals, the reliability of HFO detection was significantly higher in N3 than in N2 sleep (Wilcoxon signed-rank, 5-min: $p=0.005, z=2.8$; 10-min: $p=0.013$, $z=2.5$; 15-min: $p=0.009, z=2.6)$.

For N3 sleep, the median reliability of HFO detection increased from $67 \%$ (iqr 61 ) to $79 \%$ (iqr 59 ) to $100 \%$ (iqr $70 \%$ ) for 5-, 10- and 15-min data intervals, with significant improvement in reliability when increasing the analysed data interval length from 5 to $10 \mathrm{~min}$ (Wilcoxon signedrank, $p=0.004, z=2.9$ ), but not when increasing from 10 to 15 min (Wilcoxon signed-rank, $p=0.953, z=0.1$ ). For $\mathrm{N} 2$ sleep, the median reliability of HFO detection increased from $27 \%$ (iqr 
medRxiv preprint doi: https://doi.org/10.1101/2021.04.19.21255728; this version posted April 22, 2021. The copyright holder for this preprint (which was not certified by peer review) is the author/funder, who has granted medRxiv a license to display the preprint in perpetuity.

It is made available under a CC-BY 4.0 International license .

68 ) to $45 \%$ (iqr $73 \%$ ) to $50 \%$ (iqr $67 \%$ ) for 5-, 10- and 15-min data intervals, with significant improvement in reliability when increasing the analysed data interval length from 5 to $10 \mathrm{~min}$ (Wilcoxon signed-rank, $p<0.001, z=3.3$ ) and from 10 to 15 min (Wilcoxon signed-rank, $p=0.04$, $\mathrm{z}=2.0)$.

Across all sleep stages (N2, N3) and data interval lengths (5-15 min), we established a strong positive correlation between the HFO rates and the test-retest reliability of HFO detection (Spearman's rank correlation, $p<0.05$ ), suggesting that HFO detection is more reliable for patients with high HFO rates. However, it should be noted that longer data intervals ensure higher reliability values even for lower HFO rates. This observation suggests that longer intervals should be used for the later part of the night.

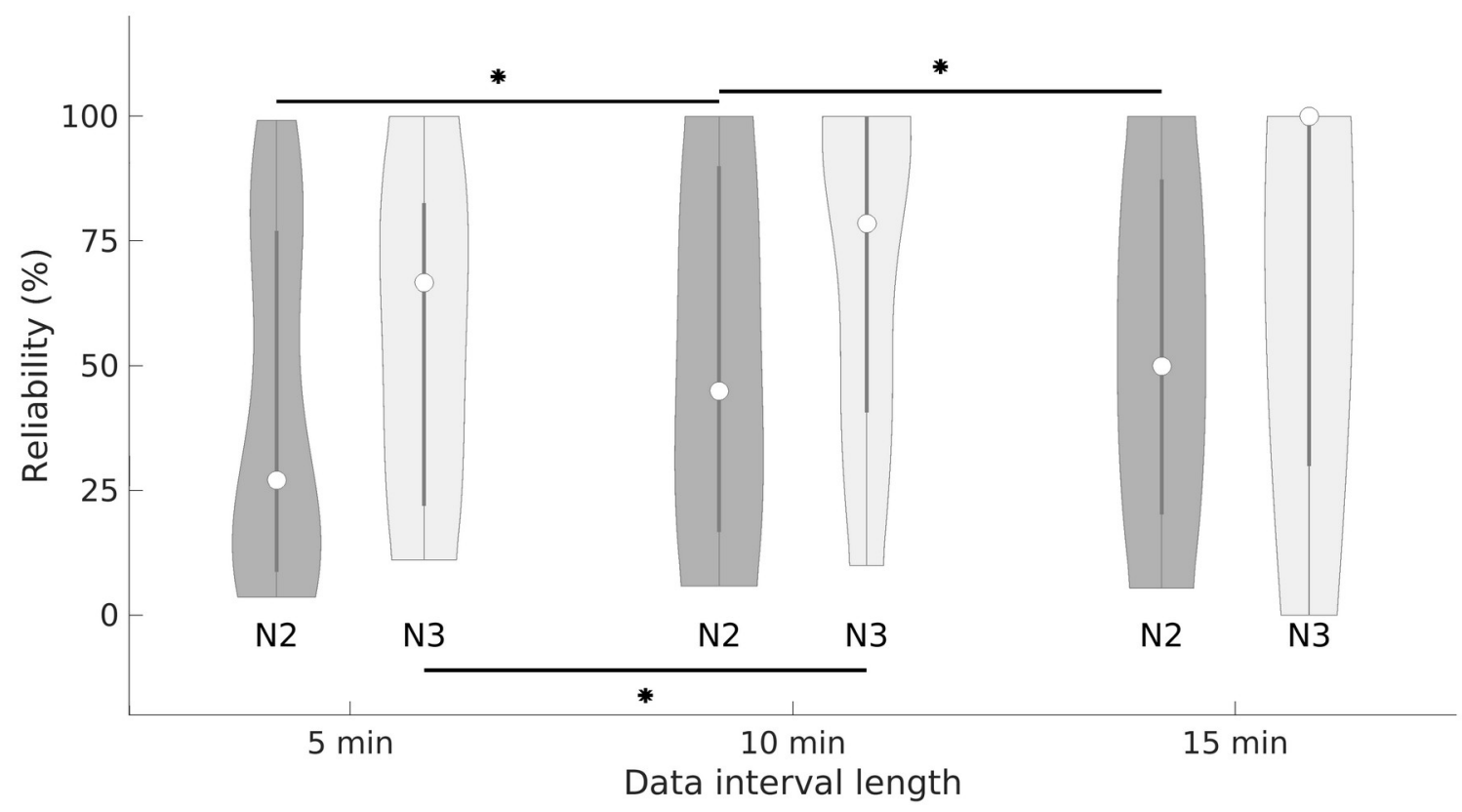

Figure 3. The test-retest reliability of HFO detection increases with the data interval length.

The violin plot shows the median (white circle) and the interquartile range (gray perpendicular line) for each distribution. For N3 sleep, the median reliability rate of HFO detection increased from $67 \%$ (iqr 61 ) to $79 \%$ (iqr 59) to $100 \%$ (iqr $70 \%$ ) for 5-, 10- and 15-min data intervals. The reliability increased significantly when increasing the analysed data interval length from 5 to 10 min (Wilcoxon signed-rank $p=0.004$, $\mathrm{z}=2.9$ ). For $\mathrm{N} 2$ sleep, the median reliability rate of HFO detection increased from $27 \%$ (iqr 68 ) to $45 \%$ (iqr $73 \%$ ) to $50 \%$ (iqr 67\%) for 5-, 10- and 15-min data intervals. For 5-, 10-, and 15-min data intervals, the reliability of HFO detection remained significantly higher in N3 than in N2 sleep (Wilcoxon signed-rank, $p=0.005, z=2.8, p=0.013, z=2.5, p=0.009, z=2.6)$. ${ }^{*} p<0.05$. 
medRxiv preprint doi: https://doi.org/10.1101/2021.04.19.21255728; this version posted April 22, 2021. The copyright holder for this preprint (which was not certified by peer review) is the author/funder, who has granted medRxiv a license to display the preprint in perpetuity. It is made available under a CC-BY 4.0 International license.

\section{DISCUSSION}

Electrophysiological markers of pathological epileptic brain activity show distinct dynamics associated with sleep stages and amount of sleep. This study demonstrates that scalp HFO in pediatric focal epilepsy change throughout whole-night sleep EEG recordings. To our knowledge, we are the first to determine the most sensitive time window in terms of sleep stage, cycle, and data interval length to ensure the quality and reproducibility of scalp HFO detection in pediatric epilepsy. We provide evidence that the first N3 sleep stage during a whole-night scalp EEG recording yields the highest HFO rates of the whole night recording. We demonstrate that reliable measures of HFO detection can be achieved in 10-min data intervals of N3 sleep, with higher HFO rates correlating with higher reliability values. Our observations enable selecting appropriate data intervals for stable HFO estimates in the first step towards their implementation as a valid epilepsy biomarker in a clinical setting.

\section{Scalp HFO rates are higher in N3 sleep}

Scalp HFO rates were significantly higher in N3 sleep than N2 sleep in our study, in line with the significantly higher spike rates occurring in N3 sleep than other vigilance states ( $\mathrm{Ng}$ and Pavlova, 2013). We may hypothesise that the higher scalp HFO and spike rates in N3 sleep are determined by the same neuronal processes that determine the decrease of spontaneous firing rates of cortical neurons with sleep (Vyazovskiy et al., 2009).

Moreover, the effects of NREM sleep stage on HFO rates in the scalp EEG of children with focal epilepsy reported here not only confirm previous observations deriving from the invasive EEG of adult patients (von Ellenrieder et al., 2017; Al-Bakri et al., 2018) but also extend these observations to a more accessible EEG modality and a much younger age group. Our study further demonstrates that including data from N3 sleep will increase the sensitivity of HFO detection because of the higher HFO rate in this sleep stage. This increased sensitivity is crucial for using HFO rate as a novel biomarker for epilepsy in the real-world clinical setting.

Finally, the remarkably high HFO rates in N3 sleep may be at least partly attributed to higher synchronicity levels in this sleep stage. This neuronal synchronisation results in the increased slope of slow-wave activity observed in N3 sleep and the amplitude of high-frequency activity. This state results in a higher phase-amplitude coupling between high (gamma, ripple) and low (theta or lower) frequencies in this sleep stage (Amiri et al., 2016). Our study replicated the strong positive covariation of HFO rate with delta band activity in N3 sleep, as previously suggested based on invasive EEG recordings (Nonoda et al., 2016; von Ellenrieder et al., 2017).

\section{Scalp HFO rate is higher in the first sleep cycle}

The first N3 sleep stage during a whole-night scalp EEG recording in our study yielded the highest HFO rate, thus constituting the most sensitive time window for analysing HFO in pediatric epilepsy. Our findings are in line with the previously reported decrease of HFO rate with accumulated time in sleep in the invasive EEG of adults with focal epilepsy undergoing presurgical evaluation (von Ellenrieder et al., 2017), and confirm that the first sleep cycle is best suitable for studying HFO, irrespective of patient age and EEG modality. 
medRxiv preprint doi: https://doi.org/10.1101/2021.04.19.21255728; this version posted April 22, 2021. The copyright holder for this preprint

(which was not certified by peer review) is the author/funder, who has granted medRxiv a license to display the preprint in perpetuity.

It is made available under a CC-BY 4.0 International license.

The correlation of HFO rate with the accumulated time spent in sleep, in addition to their correlation with the different sleep stages, may be partly explained by the sleep-homeostatic changes in delta power showing a steady decline across the recording night (Riedner et al., 2007). This observation supports the notion that synchronisation, most pronounced during NREM slow-wave sleep, may be crucial for HFO generation (von Ellenrieder et al., 2017) and that sleep homeostatic changes in slow-wave amplitude along the night determine the HFO rate (Frauscher et al., 2015; Nonoda et al., 2016; von Ellenrieder et al., 2017).

In the animal model, the levels of glutamate in the cortical extrasynaptic space decrease during NREM sleep (Dash et al., 2009), whereas sleep deprivation leads to increased cortical excitability, resulting in a lowered threshold for epileptic activity (Badawy et al., 2006; Scalise et al., 2006). While slow-wave slopes are likely a function of neuronal synchrony, during late sleep, the periods of activity and inactivity of individual neurons became progressively less synchronised (Vyazovskiy et al., 2009).

\section{Reliability of scalp HFO detection}

To confirm the reproducibility and establish the reliability of our scalp HFO detection, we performed a test-retest analysis, as previously developed by our group (Fedele et al., 2017), investigating the spatial profile of HFO rates across several EEG data intervals from each patient.

We showed that, while for higher HFO rates reasonably high reliability is reached even when using only 5-min data intervals, for lower HFO rates, longer data segments may prove indispensable. Nevertheless, it should be noted that the analysis of 10-min data intervals of N3 sleep provides considerably higher reliability than the analysis of shorter (5-min) data intervals.

Based on the findings from our cohort, we suggest that N3 data intervals of 10 consecutive minutes are required and sufficient for a consistent estimation of the spatial distribution of scalp HFO rate in most cases. We, therefore, recommend recording and analysing at least 10 min of N3 sleep to ensure a reliable scalp HFO detection in pediatric focal lesional epilepsy. HFO analysis requires stable spatial profiles over time that accurately reflect network properties since data quality and representativity will determine the validity of results (Fedele et al., 2019). It should, however, be noted that generalising these results to other datasets remains a hypothesis, especially for non-lesional/genetic epilepsy.

\section{Future directions}

HFO have been shown to be modulated by sleep in all brain regions except for the frontal lobe in an invasive EEG study, including ten patients with frontal lobe coverage (Dümpelmann et al., 2015). To investigate the effect of lobar localisation of the HFO generator, larger cohort sizes than reported here are required.

Sleep stage but not sleep cycle has been demonstrated to determine the extent of HFO spread in an invasive EEG study focussing on the effect of sleep homeostasis on HFO (von Ellenrieder et al., 2017). Whilst standard EEG does not allow for evaluating such localised effects, similar questions may be investigated using high-density scalp EEG in the future (Fan et al., 2021). 
medRxiv preprint doi: https://doi.org/10.1101/2021.04.19.21255728; this version posted April 22, 2021. The copyright holder for this preprint (which was not certified by peer review) is the author/funder, who has granted medRxiv a license to display the preprint in perpetuity. It is made available under a CC-BY 4.0 International license.

This outlook is especially relevant for the clinical setting, as high-density scalp EEG can be readily implemented in clinical epilepsy units (Zelmann et al., 2014).

\section{CONCLUSION}

Our study provides a robust and reliable framework for implementing scalp HFO as an EEG biomarker in pediatric epilepsy. Based on our findings, restricting HFO analysis to 10-min data intervals of N3 sleep can increase the diagnostic yield while condensing the EEG recording time since these carefully selected segments should suffice for clinically meaningful results. This step would permit the application of scalp HFO in the screening of children at risk of developing epilepsy as biomarkers in the estimation of prognosis and question of treatment. Non-invasively detected scalp HFO may prove an essential resource for clinical assessment in a broad population of children affected by epilepsy.

\section{ACKNOWLEDGMENTS}

We thank B. Alessandri, C. Carosio, L. Glaser, P. Hieber, and G. Selmin for their assistance with EEG recordings and data analysis. We thank the Swiss National Science Foundation (CRSK-3_190895 to G.R. and J.S.) and the Swiss League Against Epilepsy (Research Recognition Award to G.R.) for funding. The funders had no role in the design or analysis of the study.

\section{AUTHOR CONTRIBUTIONS}

D.C. analysed data. D.C. and G.R. prepared figures and tables. R.R. and G.R. treated patients and monitored outcome. P.LB. acquired data. G.R. designed and supervised the study. D.C., J.S. and G.R. wrote the article. All authors critically reviewed the manuscript.

\section{COMPETING INTERESTS}

The authors declare that they have no competing interests.

\section{PATIENT CONSENT}

The collection of patient data and the scientific analysis were approved by and performed according to the guidelines and regulations of the local ethics committee (Kantonale Ethikkommission Zürich, KEK-ZH PB-2016-02055). All patients and their parents gave written informed consent before participating in the study.

\section{CODE AVAILABILITY}

The software for the detection of HFO is freely available at the GitHub repository (https://github.com/ZurichNCH/Automatic-High-Frequency-Oscillation-Detector). Further available data and code is indexed on our website https://hfozuri.ch 
medRxiv preprint doi: https://doi.org/10.1101/2021.04.19.21255728; this version posted April 22, 2021. The copyright holder for this preprint (which was not certified by peer review) is the author/funder, who has granted medRxiv a license to display the preprint in perpetuity.

\section{REFERENCES}

Al-Bakri AF, Yaghouby F, Besio W, Ding L, Modur P, Sunderam S. Effect of Vigilance Changes on the Incidence of High Frequency Oscillations in the Epileptic Brain. Annu Int Conf IEEE Eng Med Biol Soc 2018; 2018: 991-4.

Amiri M, Frauscher B, Gotman J. Phase-Amplitude Coupling Is Elevated in Deep Sleep and in the Onset Zone of Focal Epileptic Seizures. Front Hum Neurosci 2016; 10: 387.

Badawy R a. B, Curatolo JM, Newton M, Berkovic SF, Macdonell R a. L. Sleep deprivation increases cortical excitability in epilepsy: syndrome-specific effects. Neurology 2006; 67: 101822.

Bagshaw AP, Jacobs J, LeVan P, Dubeau F, Gotman J. Effect of sleep stage on interictal highfrequency oscillations recorded from depth macroelectrodes in patients with focal epilepsy. Epilepsia 2009; 50: 617-28.

Bernardo D, Nariai H, Hussain SA, Sankar R, Salamon N, Krueger DA, et al. Visual and semiautomatic non-invasive detection of interictal fast ripples: A potential biomarker of epilepsy in children with tuberous sclerosis complex. Clin Neurophysiol 2018; 129: 1458-66.

Berry RB, Brooks R, Gamaldo C, Harding SM, Lloyd RM, Quan SF, et al. AASM Scoring Manual Updates for 2017 (Version 2.4). J Clin Sleep Med 2017; 13: 665-6.

Boran E, Sarnthein J, KrayenbühI N, Ramantani G, Fedele T. High-frequency oscillations in scalp EEG mirror seizure frequency in pediatric focal epilepsy. Sci Rep 2019; 9: 16560.

Burnham KP, Anderson DR. Model Selection and Multimodel Inference: A Practical InformationTheoretic Approach [Internet]. 2nd ed. New York: Springer-Verlag; 2002[cited 2021 Apr 7] Available from: https://www.springer.com/de/book/9780387953649

Chen Z, Grayden DB, Burkitt AN, Seneviratne U, D'Souza WJ, French C, et al. Spatiotemporal Patterns of High-Frequency Activity $(80-170 \mathrm{~Hz})$ in Long-Term Intracranial EEG. Neurology 2021; 96: e1070-81.

Cserpan D, Boran E, Lo Biundo SP, Rosch R, Sarnthein J, Ramantani G. Scalp high-frequency oscillation rates are higher in younger children [Internet]. Brain Communications 2021[cited 2021 Mar 24] Available from: https://doi.org/10.1093/braincomms/fcab052

Dash MB, Douglas CL, Vyazovskiy VV, Cirelli C, Tononi G. Long-term homeostasis of extracellular glutamate in the rat cerebral cortex across sleep and waking states. J Neurosci 2009; 29: 620-9.

Dümpelmann M, Jacobs J, Schulze-Bonhage A. Temporal and spatial characteristics of high frequency oscillations as a new biomarker in epilepsy. Epilepsia 2015; 56: 197-206.

von Ellenrieder N, Dubeau F, Gotman J, Frauscher B. Physiological and pathological highfrequency oscillations have distinct sleep-homeostatic properties. Neuroimage Clin 2017; 14: 566-73.

Fan Y, Dong L, Liu X, Wang H, Liu Y. Recent advances in the noninvasive detection of highfrequency oscillations in the human brain. Rev Neurosci 2021; 32: 305-21.

Fedele T, Burnos S, Boran E, Krayenbühl N, Hilfiker P, Grunwald T, et al. Resection of high frequency oscillations predicts seizure outcome in the individual patient. Sci Rep 2017; 7 : 13836. 
medRxiv preprint doi: https://doi.org/10.1101/2021.04.19.21255728; this version posted April 22, 2021. The copyright holder for this preprint (which was not certified by peer review) is the author/funder, who has granted medRxiv a license to display the preprint in perpetuity.

Fedele T, van 't Klooster M, Burnos S, Zweiphenning W, van Klink N, Leijten F, et al. Automatic detection of high frequency oscillations during epilepsy surgery predicts seizure outcome. Clin Neurophysiol 2016; 127: 3066-74.

Fedele T, Ramantani G, Sarnthein J. High frequency oscillations as markers of epileptogenic tissue - End of the party? Clinical Neurophysiology 2019; 130: 624-6.

Frauscher B, von Ellenrieder N, Ferrari-Marinho T, Avoli M, Dubeau F, Gotman J. Facilitation of epileptic activity during sleep is mediated by high amplitude slow waves. Brain 2015; 138 : 1629-41.

Gliske SV, Irwin ZT, Chestek C, Hegeman GL, Brinkmann B, Sagher O, et al. Variability in the location of high frequency oscillations during prolonged intracranial EEG recordings. Nat Commun 2018; 9: 2155.

Gotman J. Can EEG Abnormalities be a Biomarker of Epileptogenesis? Epilepsy Curr 2021: 1535759721999681.

Ikemoto S, Hamano S-I, Yokota S, Koichihara R, Hirata Y, Matsuura R. Enhancement and bilateral synchronization of ripples in atypical benign epilepsy of childhood with centrotemporal spikes. Clin Neurophysiol 2018; 129: 1920-5.

Jacobs J, Zijlmans M. HFO to Measure Seizure Propensity and Improve Prognostication in Patients With Epilepsy. Epilepsy Curr 2020: 1535759720957308.

Klimes P, Cimbalnik J, Brazdil M, Hall J, Dubeau F, Gotman J, et al. NREM sleep is the state of vigilance that best identifies the epileptogenic zone in the interictal electroencephalogram. Epilepsia 2019; 60: 2404-15.

van Klink NEC, van 't Klooster MA, Leijten FSS, Jacobs J, Braun KPJ, Zijlmans M. Ripples on rolandic spikes: A marker of epilepsy severity. Epilepsia 2016; 57: 1179-89.

Klotz KA, Sag Y, Schönberger J, Jacobs J. Scalp Ripples Can Predict Development of Epilepsy After First Unprovoked Seizure in Childhood. Ann Neurol 2021; 89: 134-42.

Kobayashi K, Akiyama T, Oka M, Endoh F, Yoshinaga H. A storm of fast $(40-150 \mathrm{~Hz})$ oscillations during hypsarrhythmia in West syndrome. Ann Neurol 2015; 77: 58-67.

Kramer MA, Ostrowski LM, Song DY, Thorn EL, Stoyell SM, Parnes M, et al. Scalp recorded spike ripples predict seizure risk in childhood epilepsy better than spikes. Brain 2019; 142: 1296-309.

Nagasawa T, Juhász C, Rothermel R, Hoechstetter K, Sood S, Asano E. Spontaneous and visually driven high-frequency oscillations in the occipital cortex: intracranial recording in epileptic patients. Hum Brain Mapp 2012; 33: 569-83.

Nariai $H$, Hussain SA, Bernardo D, Motoi $H$, Sonoda M, Kuroda N, et al. Scalp EEG interictal high frequency oscillations as an objective biomarker of infantile spasms. Clin Neurophysiol 2020; 131: 2527-36.

$\mathrm{Ng} \mathrm{M}$, Pavlova M. Why are seizures rare in rapid eye movement sleep? Review of the frequency of seizures in different sleep stages. Epilepsy Res Treat 2013; 2013: 932790.

Nonoda Y, Miyakoshi M, Ojeda A, Makeig S, Juhász C, Sood S, et al. Interictal high-frequency oscillations generated by seizure onset and eloquent areas may be differentially coupled with different slow waves. Clin Neurophysiol 2016; 127: 2489-99. 
medRxiv preprint doi: https://doi.org/10.1101/2021.04.19.21255728; this version posted April 22, 2021. The copyright holder for this preprint (which was not certified by peer review) is the author/funder, who has granted medRxiv a license to display the preprint in perpetuity.

It is made available under a CC-BY 4.0 International license .

Ohuchi Y, Akiyama T, Matsuhashi M, Kobayashi K. High-frequency oscillations in a spectrum of pediatric epilepsies characterized by sleep-activated spikes in scalp EEG. Clin Neurophysiol 2019; 130: 1971-80.

Riedner BA, Vyazovskiy VV, Huber R, Massimini M, Esser S, Murphy M, et al. Sleep homeostasis and cortical synchronization: III. A high-density EEG study of sleep slow waves in humans. Sleep 2007; 30: 1643-57.

Scalise A, Desiato MT, Gigli GL, Romigi A, Tombini M, Marciani MG, et al. Increasing cortical excitability: a possible explanation for the proconvulsant role of sleep deprivation. Sleep 2006; 29: 1595-8.

Staba RJ, Wilson CL, Bragin A, Jhung D, Fried I, Engel J. High-frequency oscillations recorded in human medial temporal lobe during sleep. Ann Neurol 2004; 56: 108-15.

Toda Y, Kobayashi K, Hayashi Y, Inoue T, Oka M, Endo F, et al. High-frequency EEG activity in epileptic encephalopathy with suppression-burst. Brain Dev 2015; 37: 230-6.

Tsuchiya H, Endoh F, Akiyama T, Matsuhashi M, Kobayashi K. Longitudinal correspondence of epilepsy and scalp EEG fast $(40-200 \mathrm{~Hz})$ oscillations in pediatric patients with tuberous sclerosis complex. Brain Dev 2020; 42: 663-74.

Vyazovskiy VV, Olcese U, Lazimy YM, Faraguna U, Esser SK, Williams JC, et al. Cortical firing and sleep homeostasis. Neuron 2009; 63: 865-78.

Zelmann R, Lina JM, Schulze-Bonhage A, Gotman J, Jacobs J. Scalp EEG is not a blur: it can see high frequency oscillations although their generators are small. Brain Topogr 2014; 27 : 683-704.

Zijlmans M, Worrell GA, Dümpelmann M, Stieglitz T, Barborica A, Heers M, et al. How to record high-frequency oscillations in epilepsy: A practical guideline. Epilepsia 2017; 58: 1305-15. 